\title{
Unintended durotomy during degenerative lumbar spine surgery (Incidence and management)
}

\author{
Tarik AbdulWahid* \\ Ali T. AbdulWahid** \\ Ammar Salah***
}

\author{
FRCS \\ MBChB, FIBMS \\ MBChB , FIBMS
}

\section{Summary:}

Background: Unintended durotomy is an infrequent but well-recognized Complication during degenerative lumbar spine surgery. The current literatures report a wide variation in incidence of durotomy during degenerative lumbar spine surgery.

Objective: To assess the incidence, treatment, clinical consequence, complications of unintended durotomy during degenerative lumbar spine surgery, and the results of 2-24 months clinical follow-up.

Fac Med Baghdad 2014 Vol.56, No.4 Received: Sept., 2014 Accepted Nov., 2014
Patients and Methods: A prospective study was conducted on 264 patients who underwent degenerative lumbar spine surgery performed in Al-Sheikh Zayed Hospital and private nursing home hospital- medical city in Baghdad from January 2011 to June 2012. Patients managed by spine fixation were excluded from this study.

Results: The incidence of unintended durotomy during spine surgery was 8.33\% (22 of 264 cases). The incidence varies according to the type of surgery being performed (6.66\% in primary discectomy, $12.5 \%$ in decompressive laminectomy and $21.73 \%$ in revision surgery). Unintended durotomy was more common in revision surgery compared with primary surgery $(21.73 \%$ vs $7.05 \% ; p<.001)$, and it was significantly more common among elderly patients $(17.39 \%$ in patients $>60$ years old; $\mathrm{p}=.006)$. Most of the durotomies were managed by primary repair. A mean follow-up of 6 months showed good long-term clinical results.

Conclusions: All unintended durotomies must be repaired primarily. Durotomies that were immediately recognized and treated did not lead to any significant sequelae at a mean follow-up of 6 months.

Key Words: degenerative lumbar spine surgery, unintended durotomy, CSF leak.

\section{Introduction:}

Unintended (incidental) tear of the dural sac and subsequent CSF leak is Possibly the most common intraoperative complication of lumbar spine surgery. (1) Previous studies have shown that potentially serious problems such as pseudomeningocele, CSF fistula formation, meningitis and arachnoiditis with subsequent chronic pain are all related to dural tears and CSF leakage after spinal surgery.(2) In primary surgery, it can be caused by eroded or thin dura, adhesion, fibrosis, or redundancy in cases of spinal stenosis. A history of multiple injections can alert the surgeon to many of these potential problems. In revision surgery, direct dural scarring can be found in addition to the above. It may be difficult to peel off the scar from the dura in many cases. (3) The current literature reports a wide variation in rates of durotomy in spine surgery. The reported incidence varies from as low as $2.2 \%$ to as high as $14 \%$. Most commonly, direct trauma or laceration causes dural tears during spinal surgery. Dural entry is much more common in revision procedures, usually because of adhesions in the epidural space, dural scarring,

*Private Nursing Home Hospital -Medical City.

** Dept of Surgery., Medical College -Baghdad University-. azdh-1978@yahoo.com

***Neuroscience Hospital. and loss of surgical landmarks.(4).

Excessive traction on severely herniated discs and anatomically incorrect screw placement have also been described as causative factors for dural laceration.(5)

intraoperatively secondary to an incomplete breech of the arachnoid membrane, and CSF leakage will occur postoperatively with increases in intradural pressure.(6) The most important aspect of treating a CSF leak is prevention. Careful preoperative planning and meticulous surgical technique should be exercised, particularly in patients at high risk for dural tears such as those with surgical revisions. (9) A variety of suture materials have been advocated,(10) Given the fact that not all dural tears will be recognized and repaired adequately intraoperatively, the need for postoperative treatment strategies still exists. (9) Surgical reopening and reclosure of incidental durotomies have traditionally been considered the definitive treatment. (11) Bed rest is frequently the first step in their conservative management. Abdominal binders and focal compression have been shown to be helpful in the conservative treatment of pseudomeningocele. (12) Lumbar drainage of 120 to $360 \mathrm{~mL} /$ day for 3 to 5 days has been associated with a complete resolution in $90 \%$ to $92 \%$ of cases. (13) Studies have shown complete resolution of a CSF fistula with bed rest, a watertight skin closure, and 
some form of ancillary CSF diversion. $(12,14)$ Epidural blood patching, which is frequently used for spinal headache, has been reported to successfully treat postoperative CSF fistulas and pseudomeningoceles. (14,15) Patel and colleagues described successful treatment in which three of six cases with postoperative CSF fistulas were treated with a percutaneous fibrin sealant. (16) Despite the frequency of dural tears in spinal surgery, meningitis is a rare complication reported to occur with a frequency of $0.18 \%$ of all spinal procedures. (17) In the setting of a persistent CSF fistula, the risk of meningitis, epidural abscess, arachnoiditis, delay of wound healing, or wound infection are all significantly increased. (18) With pseudomeningocele formation, localized nerve root entrapment or adhesions may produce radicular symptoms.(19) A dural tear may allow herniation of nerve roots increasing the risk of nerve root injury, which may cause chronic pain, bladder/bowel and/or sexual dysfunction, motor and sensory deficits. (20) Incidental durotomy has been demonstrated to have an association with intracranial hypotension, tonsillar herniation, and subdural hematoma or hygroma formation. (21)

\section{Patients and methods:}

This is a prospective study which included 264 patients, whom had lumbar spine surgery, Performed between January 2011 and June 2012 in Al-Sheikh Zayed Hospital in Baghdad. Patients managed by spine fixation were excluded 22 patients of them had intraoperative unintended durotomy. Of the important variables that had been analyzed were patient's ages, sex, and history of previous lumbar surgery,the primary diagnosis, details of the surgical procedure, details of the unintended durotomy and its management,postoperative clinical evaluation and follow up. Those variables were carefully analyzed and compared to previous studies to assess how they affect the incidence and clinical outcome in unintended durotomy during degenerative lumbar spine surgery. The type of operations was primary discectomy, decompressive laminectomy and revision surgeries. No magnification was used. No drains had been used. The durotomies (when recognized intraoperatively) were managed by immediate repair in most of cases, except 3 cases that were left without suturing. The latter 3 cases were managed by bed rest, prophylactic antibiotics, analgesia, and carbonic anhydrase inhibitor. The follow up started from immediate postoperative period and ranged from 2 months to 2 years. The "Statistical Package for the Social Sciences" (SPSS) software (version 21) Was used for data entry and data analysis. The results were presented using frequency tables. To measure the association we use chi-square test. Logistic regression analysis was applied to identify the most significant potential risk factors that can affect the incidence of unintended durotomy. $\mathrm{P}$ value of $<0.05$ was considered significant.

\section{Results:}

Table 1: Gender distribution and incidence of unintended durotomy during DLSS

\begin{tabular}{cccc}
\hline Gender & DLSS & Durotomy & Incidence \\
\hline Male & 146 & 11 & $7.53 \%$ \\
\hline Female & 118 & 11 & $9.32 \%$ \\
\hline
\end{tabular}

The incidence of unintended durotomy during DLSS was higher in female Patients (9.32\%) compared to male patients (7.53\%)

Table 2: Age distribution and incidence of durotomy during DLSS

\begin{tabular}{cccc}
\hline Age & Patients & Durotomy & Incidence \\
\hline$<30$ & 23 & 1 & $4.43 \%$ \\
\hline $30-39$ & 105 & 4 & $3.80 \%$ \\
\hline $40-49$ & 72 & 7 & $9.72 \%$ \\
\hline $50-59$ & 41 & 6 & $14.63 \%$ \\
\hline$>60$ & 23 & 4 & $17.39 \%$ \\
\hline
\end{tabular}

When stratified by patient age, the incidence of durotomy varied from a minimum of 3.8\% (4 of 105 cases) among patients 30 to 39 years of age to a maximum of $17.39 \%$ (4 of 23 cases) in those $>60$ years of age.

Table 3: Incidence of durotomy in DLSS based on primary diagnosis

\begin{tabular}{cccc}
\hline Type of Surgery & Patients & Durotomy & Incidence \\
\hline Primary Discectomy & 225 & 15 & $6.66 \%$ \\
\hline Decompressive Laminectomy & 16 & 2 & $12.5 \%$ \\
\hline Revision Surgery & 23 & 5 & $21.73 \%$ \\
\hline All Lumbar Surgeries & 264 & 22 & $8.33 \%$ \\
\hline
\end{tabular}

The overall incidence of unintended durotomy in this study was $8.33 \%$ (22

of 264 patients).

Table 4: Type of management of unintended durotomy according to time of diagnosis

\begin{tabular}{ccc}
\hline Time of Diagnosis & Patients & Type of Management \\
\hline $\begin{array}{c}\text { Intraoperative } \\
\text { CSF leak }\end{array}$ & 20 & $\begin{array}{c}17 \text { patients managed by } \\
\text { immediate repair } \\
\text { 3 patients left without repair }\end{array}$ \\
\hline $\begin{array}{c}\text { Postoperative } \\
\text { CSF leak }\end{array}$ & 2 & $\begin{array}{c}1 \text { patient managed } \\
\text { conservatively }\end{array}$ \\
\hline
\end{tabular}

20 patients that had unintended durotomy were recognized intraoperatively, 17 patients of them were managed and repaired immediately, while 3 patients were left without repair. 
Table 5: Postoperative sequelae after management of unintended durotomy.

\begin{tabular}{ccc}
\hline Postoperative Sequelae & Patients & Percentage \\
\hline Uneventful & 18 & $81.82 \%$ \\
\hline Mild Complications & 3 & $13.64 \%$ \\
\hline Severe Complications & 1 & $4.54 \%$ \\
\hline
\end{tabular}

After management of unintended durotomy, most of the patients $81.82 \%$ (18 of 22 patients) had uneventful postoperative period, And only 4.54\% (1 of 22 patients) had persistent CSF leak and wound dehiscence that were surgically managed after 2 weeks from the primary surgery.

\section{Discussion:}

In this study the incidence of unintended durotomy during DLSS was higher in female Patients (9.32\%) compared to male patients $(7.53 \%$ ) (Table 1), but no statistical Significant association was gained between the incidences of unintended durotomy and gender differences $(P=0.603)$. There are no comparable results in the references or previous literatures. When stratified by patient age, the incidence of unintended durotomy was significantly affected by patient's age $(17.39 \%$ in patients > 60 years old; $p=.006$ ); Which is consistent with previously published literatures. (Table 2) The incidence of unintended durotomy in different studies is shown in Table. (4-1). (6, 22, and 25).

Table 4-1: Literature Review of the Incidence of Unintended Durotomy Occurring During Lumbar Spinal Surgery

\begin{tabular}{cccc}
\hline Study & $\begin{array}{c}\text { Number of } \\
\text { patients }\end{array}$ & $\begin{array}{c}\text { Unintended } \\
\text { Durotomy }\end{array}$ & Incidence \\
\hline Cammisa et al. ${ }^{(6)}$ & 1715 & 64 & $3.7 \%$ \\
\hline Epstein et al. ${ }^{(25)}$ & 110 & 10 & $9.1 \%$ \\
\hline Stolke et al. ${ }^{(22)}$ & 481 & 26 & $5.4 \%$ \\
\hline
\end{tabular}

In this study, the overall incidence of unintended durotomy in degenerative lumbar spine surgery were 8.33\% (22 of 264 patients) (Table 3), which is comparable with previously published literatures. This study shows the rates of unintended durotomy were $6.66 \%$ for primary discectomy, $12.5 \%$ for spinal stenosis surgery and $21.73 \%$ for revision surgery (Table 3). The incidence of unintended durotomy in primary discectomy and decompressive laminectomy are comparable to those in the literature,
Table 4-2: The incidence of unintended durotomy of commonly performed degenerative lumbar spine surgery of this study in comparison to those in the literature

\begin{tabular}{ccc}
\hline Type of Surgery & $\begin{array}{c}\text { Incidence of } \\
\text { unintended } \\
\text { durotomy in this } \\
\text { study }\end{array}$ & $\begin{array}{c}\text { Incidence of } \\
\text { unintended durotomy } \\
\text { in previous literatures }\end{array}$ \\
\hline $\begin{array}{c}\text { Primary } \\
\text { Discectomy }\end{array}$ & $6.66 \%$ & $1-7.1 \%$ \\
\hline $\begin{array}{c}\text { Decompressive } \\
\text { Laminectomy }\end{array}$ & $12.5 \%$ & $3.1-13 \%$ \\
\hline $\begin{array}{c}\text { Revision } \\
\text { Surgery }\end{array}$ & $21.73 \%$ & $8.1-17.4 \%$ \\
\hline $\begin{array}{c}\text { All Lumbar } \\
\text { Surgeries }\end{array}$ & $8.33 \%$ & $1-17 \%$ \\
\hline
\end{tabular}

While the incidence of unintended durotomy occurring during revision spine surgery as reported in this study is $21.73 \%$ (Table 3); which is higher than those in the literature, that range from $8.1 \%(23)$ to $17.4 \%(22)$ (Table $4-2)$. Revision surgery was associated with a significantly greater (about 3 times) incidence of unintended durotomy (21.73\%) compared with primary surgery $(7.05 \%$; $\mathrm{P}$.001) (Table 3$)$. In this study, 20 cases $(90.9 \%)$ of unintended durotomy were recognized at the time of surgery, while only 2 cases $(9.1 \%)$ were missed intraoperatively and presented as postoperative CSF leak, one of them had been managed conservatively and the other one were managed by surgical repair (Table 4). The use of drains is controversial. Eismont et al. (23) advised against placement of subfascial drains because it could precipitate the formation of a durocutaneous fistula. Cammisa et al. (24) reported their use of drain is dependent on the procedure, the size of the dural tear, the tissue quality and the quality of the repair. Wang et al. (22) placed a drain in all cases. Khan et al. (7) used subfascial drains in most cases. A subarachnoid drain can be an alternative for the treatment of postoperative CSF leak (23) or chronic pseudomeningocele. (64) In this study, no drain has been used in all the cases of unintended durotomies. Eismont et al. (23) et found that bed rest without surgical repair was an unsuccessful method of treatment for unrepaired dural tears. Cammisa et al. (24) used bed rest ranging from 3 to 5 days in all patients. In this study, bed rest has been applied to all patients with unintended durotomy for variable periods of time ranging from 5-14 days (average of 7.5day). In this study, after management of unintended durotomy, most of the patients $81.82 \%$ (18 of 22 patients) had uneventful postoperative period, while 13.64\% (3 of 22 patients) had mild postoperative complications in the form of mild backache, headache or nausea that resolved within few days (Table 5). And only 4.54\% (1 of 22 patients) had persistent CSF leak and wound dehiscence that were surgically 
managed after 2 weeks from the primary surgery. The surgery was primary discectomy. In their study, Wang et al. had a 2.3\% reoperation rate (2 of 88 patients; both were revision cases). Similarly, Camissa et al. (24) had a reoperation rate of9.1\% (6 of 66 patients). In comparison, only $4.54 \%$ (1 of the 22 durotomy cases in this study) required reexploration and repair of the defect.

\section{Conclusions:}

Unintended durotomy is a well-known complication of spine surgery, and it occurs even among experienced spine surgeons. The incidence of unintended durotomy in DLSS was significantly affected by patient's age, the incidence increases with advancing ages. The overall incidence of unintended durotomy in this study was $8.33 \%$. Based on primary diagnosis, the incidence was $6.66 \%$ in primary discectomy, $12.5 \%$ in decompressive laminectomy. Revision surgery was associated with a significantly greater (about 3 times) incidence of unintended durotomy compared with primary surgery. The gold standard treatment for incidental durotomies is primary repair with a watertight closure. Durotomies that were immediately recognized and treated did not lead to significant sequelae or complications differ from those patients without durotomy.

Recommendations:

Prevention is the most effective way to minimize the incidence of unintended durotomy and its complications. Prevention can be achieved by careful preoperative planning and meticulous surgical technique. Magnification instruments (microscope or loupes) can be used. Before closure, the anesthesiologist can be asked to increase the intra thecal pressure to reveal any subtle durotomy and CSF leak. The use of dura seal is advisable to decrease the incidence of CSF leakage after durotomy repair, and to lessen epidural adhesions.Spine surgeons must be aware of the risks related to dural tears and CSF leak.Patients must be informed of these complications before undergoing spine surgery, especially in revision surgery.

\section{Author contributions:}

Dr.Tarik AbdulWahid: Study conception, Critical revision Dr.Ali Tarik AbdulWahid.: .Study design, Interpretation of data

Dr.Ammar Salah.: Acquisitions of data analysis, Drafting of manuscript.

\section{References:}

1. Eismont FJ, Herkowitz, HN. Rothman-Simeone - The Spine, Philadelphia, WB Saunders, 6th Edition 2011; 95:18201725.

2. Goodkin R, Laska LL.Unintended "incidental” durotomy during surgery of the lumbar spine: medicolegal implications. SurgNeurol 43:4-12, 1995.

3. Aydinli U, Karaeminogullari O, Tiskaya K, et al: Dural tears in lumbar burst fractures with greenstick lamina fractures. Spine 26:E410-E415, 2001.

4. Morris GF, Marshall LF: Cerebrospinal fluid leaks: Etiology and treatment. In Herkowitz HN, Garfin SR, Balderston RA, et al (eds): Rothman-Simeone: The Spine. Vol 2. Ed 4. Philadelphia, WB Saunders, 1999, pp 1733-1739.

5. Bosacco SJ, Gardner MJ, Guille JT: Evaluation and treatment of dural tears in lumbar spine surgery. ClinOrthopRelat Res 2001:238-247.

6. Cammisa FP, Jr., Girardi FP, Sangani PK, et al: Incidental durotomy in spine surgery. Spine 25:2663-2667, 2000.

7.http://www.springerimages.com/Images/RSS/1-10.1007_ s00586-009-1219-y-1

8. Johnson DB, Brennan P, Toland J, et al: Magnetic resonance imaging in the evaluation of cerebrospinal fluid fistulae. ClinRadiol 51:837-841, 1996.

9. Vanaclocha V, Saiz N, Panta F. Repair of dural defects in awkward areas-technical note. ActaNeurochir (Wien) 1998;140:615-618.

10. Wang JC, Bohlman HH, Riew KD.Dural tears secondary to operations on the lumbar spine. J Bone Joint Surg 1998;80A(12):1728-1732. \{ IVSL, high wire \}.

11. Leis AA, Leis JM, Leis JR: Pseudomeningoceles: a role for mechanical compression in the treatment of dural tears. Neurology 56:1116-1117, 2001.

12. Shapiro SA, Scully T: Closed continuous drainage of cerebrospinal fluid via a lumbar subarachnoid catheter for treatment or prevention of cranial/spinal cerebrospinal fluid fistula. Neurosurgery 30:241-245, 1992.

13. Waisman M, Schweppe Y: Postoperative cerebrospinal fluid leakage after lumbar spine operations: Conservative treatment. Spine 16:52-53, 1991.

14. Elbiaadi-Aziz N, Benzon HT, Russell EJ, et al: Cerebrospinal fluid leak treated by aspiration and epidural blood patch under computed tomography guidance. RegAnesth Pain Med 26:363-367, 2001.

15. Maycock NF, van Essen J, Pfitzner J: Post-laminectomy cerebrospinal fluid fistula treated with epidural blood patch. Spine 19:2223-2225, 1994.

16. Patel MR, Louie W, Rachlin J: Postoperative cerebrospinal fluid leaks of the lumbosacral spine: management with percutaneous fibrin glue. AJNR Am J Neuroradiol 17:495500, 1996. \{ IVSL, high wire \}.

17. Twyman RS, Robertson P, Thomas MG: Meningitis complicating spinal surgery. Spine 21:763-765, 1996.

18. Koo J, Adamson R, Wagner FC, Jr., et al: A new cause of chronic meningitis: infected lumbar pseudomeningocele. Am J Med 86:103-104, 1989. 
19. O'ConnorD, MaskeryN, Griffiths WE: Pseudomeningocele nerve root entrapment after lumbar discectomy. Spine 23:1501-1502, 1998.

20. Pereira Filho Ade A, David G, Pereira FilhoGde A, et al: Symptomatic thoracic spinal cord compression caused by postsurgical pseudomeningocele. ArqNeuropsiquiatr 65:279282,2007.

21. Sciubba DM, Kretzer RM, Wang PP: Acute intracranial subdural hematoma following a lumbar CSF leak caused by spine surgery. Spine 30:E730-E732, 2005.

22. Stolke D, Sollmann WP, Seifert V: Intra- and postoperative complications in lumbar disc surgery. Spine 14:56-59, 1989. 23. Eismont FJ, Wiesel SW, Rothman RH.Treatment of dural tears associated with spinal surgery. J Bone Joint Surg 1981;63A:1132-6.

56 24.Camissa FP, Girardi FP, Sangani PK et al (2000) Incidental durotomy in spine surgery. Spine 25(20):26632667

25. Epstein NE: The frequency and etiology of intraoperative dural tears in 110 predominantly geriatric patients undergoing multilevel laminectomy with noninstrumented fusions. J Spinal Disord Tech 20:380-386, 2007. 